\title{
Anatomy Observational Outreach: A Multimodal Activity to Enhance Anatomical Education in Undergraduate Students
}

\author{
Monica Mathis ${ }^{1}$, Maryvi Gonzalez-Sola ${ }^{2}$, and Martin Rosario ${ }^{1,+}$ \\ 'Texas Woman's University School of Physical Therapy, Dallas, Texas, USA \\ ${ }^{2}$ West Coast University General Education Department, Dallas, Texas, USA \\ ${ }^{+}$Corresponding author: Martin G. Rosario PT, PhD. (mrosario1@twc.edu) Postal Address: TWU Physical \\ Therapy Department, 5500 Southwestern Medical Avenue, Dallas, TX, 75235 \\ DOI: $10.47611 /$ jsr.v9i1.869
}

\section{ABSTRACT}

Undergraduate students often have difficulty relating the Anatomy and Physiology (A\&P) course to their future careers, which may lead to difficulties in graduate school. Thus, the purpose of the Anatomy Observational Outreach (AOO) was to help students make the connection and application between the information presented in A\&P labs and real human cadaver, which could encourage students to pursue graduate degrees. The outreach consisted of 99 undergraduate A\&P students from Texas Woman's University in the biology, nursing, kinesiology, health studies, physical therapy, and occupational therapy departments. The methodology consisted of a 30-minute orientation, a graduate student panel, a Q\&A session, a 60-minute cadaver observation, and Anatomage table demonstration, amongst others. The impact of AOO was measured by 10-question pre-tests and identical post-tests (1 point each) along with a survey at the end. The tests result demonstrated a significant increase $[\mathrm{t}(62)=-9.3, \mathrm{p}=0.001]$ in anatomical knowledge. The survey results showed that out of 99 participants, $84 \%$ of the students interested in applying to graduate school, $32 \%$ of students felt that all of the teaching tools were useful, while $68 \%$ concluded the cadaver prosections were the most potent sole educational aid. $65 \%$ of the students were ethnic minorities, and $97 \%$ were gender minorities. We conclude that $\mathrm{AOO}$ yielded distinguished results in retention, and application of A\&P knowledge, along with increased interest and excitement for pursuing a STEM and Allied Health degrees.

\section{Introduction}

Most of the undergraduate biology programs aspire to promote a proper understanding of the processes of life, its development, and its diversity. The general goal for these undergraduate biology programs is to educate students for professions in cutting-edge graduate studies or advanced preparation in the biological sciences. During a four-year program, students develop a comprehensive understanding of the principles of biological science, among other core sciences (TWU, 2019; Momsen et al., 2010; Chopin et al., 2002; Bavis et al., 2000; Bergman et al., 2008). Furthermore, the biology setting provides a foundation for those seeking admission into graduate programs in fields including, but not limited to, physical therapy, medicine, occupational therapy, and nursing.

A \& $\mathrm{P}$ is among the core courses provided in the biology departments for all science programs. These courses give students knowledge of the human body, along with exposure to animal dissections to fulfill requirements for an array of degree programs and professional applications. Also, A \& P laboratories are intended for students to follow a pre-designed guide allowing for slight application to real-world activities as students sometimes neglect to make the 
association between understanding the relevance of the course concepts and applying them to the everyday life of these laboratory activities (Chopin et al., 2002). To boot, students frequently complain about memorizing vast quantities of structures non-relevant to their goals or careers (Lunsford and Hersoy, 1997), making it a challenge to excite interest in scholars (Shigeoka et al., 2000).

Consequently, as educators, we must inquire ourselves: How do we elicit students' interest in STEM and Allied Health careers? How can we facilitate students to build the connection and application between the selective information presented in A \& P labs and real-world activities? More significantly, how do we effectively encourage students to pursue graduate degrees or Allied Health careers? To address these questions, we created the "Anatomy Observational Outreach (AOO)" based on previous evidence that anatomy outreach activities can 'have a positive influence on students (González-Solá and Rosario-Canales, 2015; Solá and Rosario, 2018). Hence, in collaboration with the Texas Woman's University Dallas Physical Therapy Graduate Program, this initiative targeted voluntary undergraduate students who held an interest in learning gross anatomy from the TWU Denton campus (TWU 2019).

The general intent of the $\mathrm{AOO}$ was to enhance the students' understanding of human anatomy via observation and identification of human cadavers to encourage students to pursue postgraduate education or Allied Health careers. The specific objectives were: first, to enhance student learning and comprehension of human anatomy with a predissected cadaver and other 3D virtual anatomy tools (such as the Anatomage table [Anatomage 2019] or PAL 3.0 [Pearson 2019]). Secondly, provide a high-quality and innovative educational experience for students with a focus on professional growth, long-term success, and measurable learning outcomes. Thirdly, use previous knowledge obtained at the undergraduate (TWU-Denton) A\&P laboratory to identify anatomical structures of body systems such as muscles, skeletal system, and nervous system. Finally, promote peer-to-peer learning between graduate and undergraduate students by using alternate strategies such as a student's panel, graduate students explaining the anatomy, and a Q\&A session.

Consequently, the $\mathrm{AOO}$ allowed for 99 students to attend the hands-on cadaver prosections, graduate student panel, and virtual anatomy dissection demonstrations. Pre-tests and post-tests were completed on location to establish the impact of this outreach activity, along with surveys to obtain the student's opinions on this experience.

\section{Methods}

\section{Participants}

The AOO activity was held at the TWU Institute of Health Sciences Graduate Programs at Dallas, TX. The AOO consisted of 99 undergraduate students from TWU main campus Denton TX. One month before AOO, A \& P students were informed of the event. If interested, students were directed to communicate with the A\&P professor and coordinator of the activity. Students who intended to partake in the AOO were given an enrollment sheet to sign-up for the outreach. The 2-hour AOO activity consisted of 1) orientation with a pre-test session, 2) an anatomy laboratory session, 3) an Anatomage (virtual dissection table) demonstration, 4) a graduate student panel, and 5) post-test and survey session.

The AOO was part of the Pioneer with a Cause Outreach Organization (PCOO). PCOO is a student local TWU Dallas Org. design to hold different outreach events throughout the year. PCOO is composed mainly of Physical Therapy students from the same campus and Mentored by a Physical Therapy Faculty professor. Both the student president (Monica Mathis) and the Mentor (Dr. Martin G. Rosario) of this Org are Co-Authors in this work.

\section{Outreach Procedures}

The AOO activity was held at the TWU Institute of Health Sciences Graduate Programs at Dallas, TX. The AOO consisted of 99 undergraduate students from TWU main campus Denton TX. One month before AOO, A \& P students 
were informed of the event. If interested, students were directed to communicate with the A\&P professor and coordinator of the activity. Students who intended to partake in the AOO were given an enrollment sheet to sign-up for the outreach. The 2-hour AOO activity consisted of 1) orientation with a pre-test session, 2) an anatomy laboratory session, 3) an Anatomage (virtual dissection table) demonstration, 4) a graduate student panel, and 5) post-test and survey session.

The AOO was part of the Pioneer with a Cause Outreach Organization (PCOO). PCOO is a student local TWU Dallas Org. design to hold different outreach events throughout the year. PCOO is composed mainly of Physical Therapy students from the same campus and Mentored by a Physical Therapy Faculty professor. Both the student president (Monica Mathis) and the Mentor (Dr. Martin G. Rosario) of this Org are Co-Authors in this work.
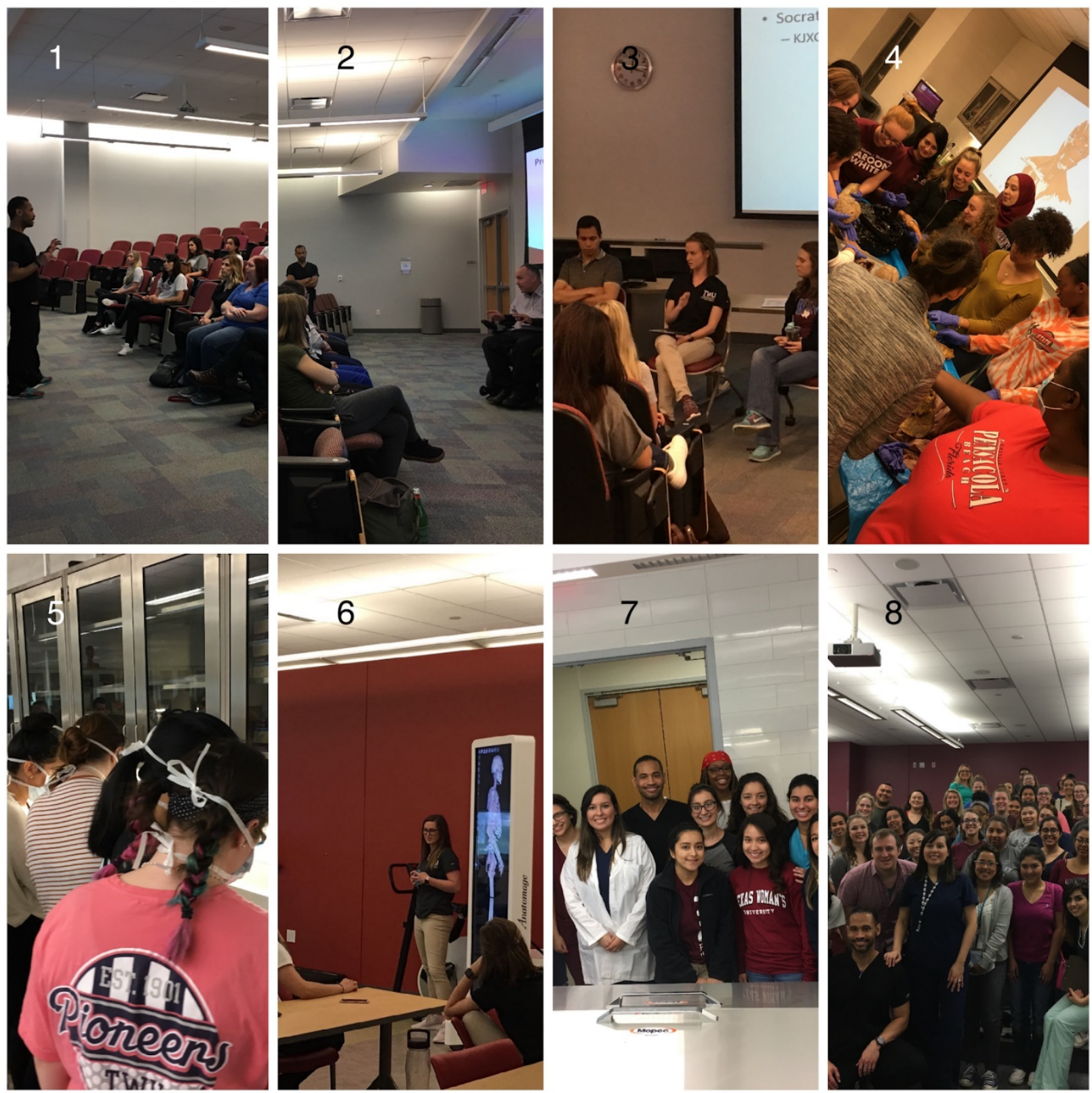

Figure 1: AOO activity; $1 \&$ 2) Orientation to the undergraduate students, 3) Student Panel, $4 \&$ 5) students in the anatomy laboratory observing the human specimens, 6) Anatomage table review of virtual cadaver and 7 \& 8) Q \& A sessions and wrap up. 


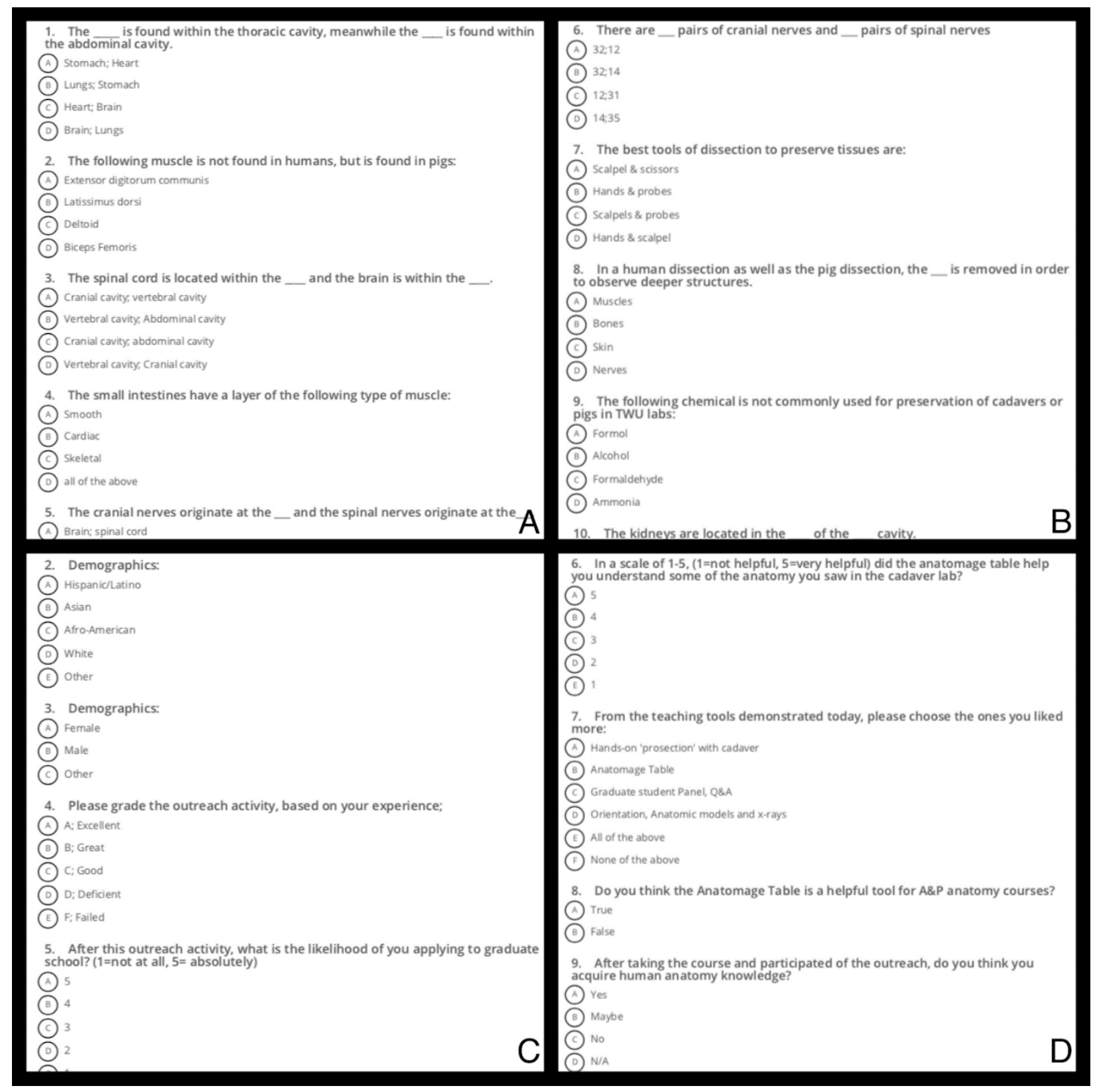

Figure 2: Questions Sample. A-B) Pre-tests and post-test questions and C-D) Survey questions to obtain feedback from students.

\section{Student Panel}

The student panel consisted of 4 graduate students from the physical therapy program, one graduate student from the occupational therapy department, and one graduate student from the nursing department. During this round, 1) the panel participants sat in chairs facing the undergraduate students as they gave detailed descriptions of their programs, courses, experiences, and career intentions. Then, 2) they held a Q\&A session to answer questions from the AOO undergraduate students. Questions raised by undergraduate pupils for the graduate scholars revolved around advice for applying to their respective programs. Life management with their educational programs. The curriculum per semester and the level of difficulty of the courses, among others. 


\section{Cadaver Laboratory Procedures}

The anatomy laboratory portion of the AOO was allotted 30-minutes per group (the total amount of time in the laboratory was 1 hour) and consisted of three stations: cadaver prosections, organ examinations, and imaging observations. 1) Students observed and prosected three pre-dissected human cadavers, on which they identified structures related to the integumentary, muscular, skeletal, and nervous systems, as per the outlined main objectives of this outreach. Students were as well able to observe the digestive, reproductive, endocrine, lymphatic, respiratory, cardiovascular, and urinary systems during the 10 minutes they were allotted at each station, before switching to the second station for another 10 minutes, after which this process was repeated for the third station. 2) On the second station, there were human cadaver organs, which included dissected brains, lungs, hearts, kidneys, livers, and spleens. 33) Lastly, the students rotated through the third and final station, which consisted of imaging like x-rays of the following joints: shoulder, elbow, knee, hip and ankle, and MRI scans of the brain observed in different anatomical planes (sagittal, transverse and coronal).

During the cadaver laboratory activity, students were encouraged to ask questions to maximize their learning experiences, thoroughly comprehend what they were observing, examining, and prosecting, along with applying their undergraduate A\&P course knowledge to the cadavers. 4) After the first 30 minutes, the two groups were interchanged so that group 1 could observe the Anatomage, a virtual anatomy dissection table, while group 2 was received in the cadaver laboratory to observe the bodies, organs, and imaging for the allotted 30-minutes. Each station was monitored and taught by the professors and graduate students during the entire 1-hour inside the laboratory.

\section{Anatomage Table Procedures}

Four anatomy-trained graduate students from the TWU Dallas PT department were in charge of explaining different anatomical aspects using the Anatomage table (Anatomage 2018) for 30 minutes for each group. This table shows a "real-life virtual human cadaver," which allows individuals to "virtually dissect" a cadaver to depict the internal structures. Therefore, the purpose was 1) Physical Therapy scholars discussed each system outlined in the objectives of the outreach to virtually teach anatomy to the undergraduate students as a "review." 2) The undergraduate pupils were then able to ask the graduate students questions while interacting with the Anatomage.

\section{Results}

In table 1, we present a sample of the agenda of the AOO activity described in the methods section, with details of the time, location, and divisions of groups and the respective activities performed. This table was the organization of the last outreach activity. The first outreach activity had a campus tour that later was replaced, per students' feedback, by the graduate students' panel. Also, after the laboratory funding was approved, the equipment was acquired, and to improve the student learning experience, we added the anatomage table to the following outreach activity.

Table 1: AOO Schedule. Time table organization and group division of AOO activity.

\begin{tabular}{|c|l|l|}
\hline Room \& Time & \multicolumn{1}{|c|}{ Group 1 } & \multicolumn{1}{|c|}{ Group 2 } \\
\hline 11. am & \multicolumn{3}{|c|}{ Arrival of undergraduate students } \\
\hline Room 2702- & $\begin{array}{l}\text { 1. Orientation by Dr. Rosario, Dr. Anderle and Dr. González } \\
\text { 2. } 11: 45 \text { am-12 pm }\end{array}$ & 3. Gre-Test \\
2. $12 \mathrm{pm}-12: 20 \mathrm{pm}$ & & \\
\hline
\end{tabular}




\begin{tabular}{|c|c|c|}
\hline $\begin{array}{l}5^{\text {th }} \text { Floor Anatomy Lab } \\
\begin{aligned} \text { 1. } & 12: 20 \mathrm{pm}-1 \mathrm{pm} \\
\text { 2. } & 1 \mathrm{pm}-1: 40 \mathrm{pm}\end{aligned}\end{array}$ & $\begin{array}{l}\text { 1. Cadaver Observation } \\
\text { 2. Anatomage Table }\end{array}$ & $\begin{array}{l}\text { 1. Anatomage Table } \\
\text { 2. Cadaver Observation }\end{array}$ \\
\hline $\begin{array}{l}\text { Room } 2702 \\
1: 40 \mathrm{pm}-2 \mathrm{pm}\end{array}$ & $\begin{array}{ll}\text { 1. } & \text { Post-Test } \\
\text { 2. } & \text { Survey } \\
\text { 3. } & \text { Q\&A session }\end{array}$ & \\
\hline
\end{tabular}

Also, out of the 99 students in attendance, 91 completed the pre-test, and 63 completed the post-test in its totality, thus allowing for $69 \%$ of the responses to be fully and successfully analyzed. After the completed pre-tests and posttests, the results demonstrated that students scored significantly higher [t(62)=-9.3, $\mathrm{p}=0.001]$ post-tests after participating in the AOO, as seen in Table 2. The survey showed that the students had an $84 \%$ interest in pursuing graduate degrees in STEM and Allied Health fields (Table 3).

Table 2: Test Results. Comparing pre-test and post-test of students before and after AOO activity.

\begin{tabular}{|l|l|l|l|l|}
\hline Variable & $\begin{array}{l}\text { pre-test } \\
(\mathbf{n = 9 1})\end{array}$ & $\begin{array}{l}\text { post-test } \\
(\mathbf{n = 6 3})\end{array}$ & t-value & p-value \\
\hline Test Score & $6.6+/-1.5$ & $8.4+/-1.4$ & 62 & $\leq 0.001$ \\
\hline
\end{tabular}

Table 3: Survey-Graduate School. Student's survey results demonstrating their intention to apply to graduate school following the outreach

\begin{tabular}{|l|l|l|}
\hline Applying to Graduate School & Number of Students (n=73) & $\%$ \\
\hline Applying & 61 & $84 \%$ \\
\hline Not Sure & 12 & $16 \%$ \\
\hline
\end{tabular}

Furthermore, though all 99 students felt that all the activities and tools (Anatomage Table, anatomical models, $\mathrm{x}$ rays, and Practice Anatomy Lab or PAL 3.0) were useful, 68\% concluded the cadaver prosections were the most potent sole educational aids (Table 4). Regarding the outreach itself, 71 students who responded to the survey, $65 \%$ were ethnic minorities (41\% Latino, 7\% Asian, 13\% African American and 4\% other), as seen in table 5. Too, from the 99 students who responded, $97 \%$ were female gender (Table 6). 
Table 4: Survey-Teaching Strategy Preference. Student's survey results demonstrating their preference of the tools used in the AOO

\begin{tabular}{|c|c|c|}
\hline \multicolumn{3}{|l|}{ Survey } \\
\hline Example of Answer Choices & Responses & Percentage \\
\hline Hands-on prosection with cadaver & 67 & $68 \%$ \\
\hline $\begin{array}{l}\text { All of the above } \\
\text { (Included: Hands-on prosection with cadaver, Anatomical models, organs, and X-rays) }\end{array}$ & 32 & $32 \%$ \\
\hline Total & 99 & $100 \%$ \\
\hline
\end{tabular}

Table 5: Ethnicity. Ethnic backgrounds of students who participated in the AOO activity.

\begin{tabular}{|l|l|l|}
\hline \multicolumn{2}{|c|}{ Ethnicity } & Percentage \\
\hline Answer Choices & Responses & $41 \%$ \\
\hline Hispanic/Latino & 29 & $7 \%$ \\
\hline Asian & & \\
\hline African American & 5 & $13 \%$ \\
\hline Caucasian/White & 9 & $35 \%$ \\
\hline Other & 25 & $4 \%$ \\
\hline Total & 3 & $100 \%$ \\
\hline
\end{tabular}


Table 6: Gender. Genders of the students who participated in the AOO

\begin{tabular}{|l|l|l|}
\hline \multicolumn{2}{|c|}{ Gender } \\
\hline Gender options & Responses & Percentage \\
\hline Male & 3 & $3 \%$ \\
\hline Female & 96 & $97 \%$ \\
\hline Total & 99 & $100 \%$ \\
\hline
\end{tabular}

Finally, in table 7, we show the results of the student who graded the AOO activity. Results indicate 64 students out of 71 students who responded to the survey graded the AOO with A, six students graded the activity with a B, and one student graded the activity with a C. Thence, $90 \%$ of the students graded this activity with A or excellent experience.

Table 7: Survey-AOO Grade. Student's survey results reporting their grading of the AOO experience

\begin{tabular}{|l|l|l|}
\hline \multicolumn{2}{|c|}{ Activity Grading } & Percentage \\
\hline Grading options & Responses & $90 \%$ \\
\hline A (Excellent) & 64 & $8.5 \%$ \\
\hline B (Great) & 6 & $1.5 \%$ \\
\hline C (Good) & 1 & $0 \%$ \\
\hline D (Deficient) & 0 & $0 \%$ \\
\hline F (Fail) & 0 & $100 \%$ \\
\hline Total & 71 & \\
\hline
\end{tabular}




\section{Discussion}

The objective of this study was to create the AOO to bring the students to the anatomy laboratory at TWU Dallas to observe the cadavers and have them discern, distinguish, and employ their anatomical knowledge with cadavers. The AOO also involved the 3D anatomy component by using tools such as the Anatomage table (www.anatomage.com) and 3D anatomy apps projected on the big screen, including PAL 3.0 (Pearson 2019), as an accompaniment to the cadaver experience.

This activity intended to give the students a different approach to A\&P courses. One of the reasons is the difficulty and challenge of teaching anatomy \& physiology at the undergraduate level due to the necessity of integrating active learning methods to forefend from memorization (Bavis et al., 2000). This report focused on undergraduate students from various scientific discipline departments at TWU who were taking an A \& P course.

Typically, other researchers notice that the use of three-dimensional computer models to teach anatomy is an excellent advantage for undergraduate students (Brenton et al., 2007). Withal, the computational 3D models lack anatomical variations that a real human cadaver can provide. Cadavers frequently demonstrate the normality that can be seen in textbooks. Human specimens as well demonstrate unique variations that make students aware of their existence, particularly for allied health careers that work with patients daily (Aziz et al., 2002).

However, teaching anatomy with human cadavers is typically reserved for medical schools or graduate schools for other allied health careers. Nonetheless, studies have shown that teaching traditional anatomy with human cadavers have better results during test-taking compared to those that exclusively rely on anatomical technology. This concept mentioned above demonstrates that, for students to succeed in their tests, 3D anatomy might be used as an adjunct to student's learning process instead of the only teaching tool (Biasutto et al., 2005). Thence, the aforementioned is one of the reasons this AOO activity wanted to acquaint the undergraduate students with the human cadaver laboratory at TWU Dallas.

Another critical reason is helping students to incorporate their anatomy into their long-term memory. Studies show that undergraduate students have a gap in anatomical knowledge when they depart to medical school, regardless of the prior teaching methods in their previous establishment (Bergmen et al., 2008; Chopin et al., 2002). Thus, the AOO aimed to create an early exposure for undergraduate students to human cadavers in order for them to interact, acquire and employ their previous A\&P knowledge in a real setting that could help them in closing the gap (Solá and Rosario, 2018).

\section{AOO procedures and results}

Ninety-nine undergraduate students from the TWU Denton campus participated in the AOO at the TWU Dallas campus. The activity began with an introduction and instructions, the pre-test, and the division of the participating undergraduate students into two groups. We observed that there was more substantial participation of minorities and females in the activity, as seen on the results of tables 5 and 6 , respectively.

Another intriguing aspect of the AOO was the graduate student panel, the amount of interaction, and the volume of questions asked by the undergraduate participants to the graduate scholars. We believe that the addition of the peer learning is vital as the participants developed new network connections and obtained feedback about the graduate school itself, as students can teach other students as a scholarship strategy (Jackson, C. K., and Bruegmann, E. 2009; Knobe et al., 2010). We contrive on continuing to provide this component of peer learning for future AOO activities.

We as well quantified student learning and knowledge by contrasting the tailored pre-test and post-test, which covered general human anatomy, along with the comparability between animal anatomy from A\&P courses and gross human anatomy. The results of the post-test showed a significant gain in learning anatomy after participating in the AOO (Table 2). This outcome demonstrated that students learned anatomy while in the AOO, achieving one of the purposes to enhance students' learning and comprehension of anatomy. 
This study measured the success of the AOO by the student's rating of the activity. Results showed that $90 \%$ of the students enjoyed the experience by rating the activity with an A (excellent) (Table 7), and none of them rated the activity with $\mathrm{D}$ (regular) or $\mathrm{F}$ (poor). This knowledge implies the success of the activity, which was demonstrated and supported by the comments and positive feedback we obtained in the survey. Moreover, we observed that although students did value the 3D anatomy components and other tools such as anatomical models and imaging (results shown in table 4 within "all the above" answer choice), their predilection remained with the cadaver prosections as the most effective teaching technique applied during the AOO.

\section{AOO survey and future directions}

In order to ascertain student's feedback to improve future AOO, a short survey was administered, with a comments section (Figure 2C and 2D). The encounter had a positive influence, as confirmed by the above results, as each person involved found value from engaging in the AOO. All students ranked heartily concur on "I loved going into the cadaver lab and seeing all the different organs. I learned so much in a little amount of time", "seeing the cadaver hands-on and not on models to get a better idea of what it looks like," and "my favorite part was going and seeing the body and speaking to the TA," among others.

Additionally, the comments given to build the future AOO better were to increase the time allotted for the graduate student panel and to increase the quantity of time inside the cadaver laboratory. This information suggests students, in addition to enjoying the activity, also learned during the AOO, but they wanted to remain longer.

Too, while cadavers have shown to render higher gross anatomical acquisition, the survey demonstrated the students conveyed the Anatomage Table is a necessary supplement to undergraduate A\&P courses. The anatomage virtual dissection table allows the students to fully dissect and study a life-size virtual cadaver without the need for a human cadaver. Although the Anatomage table is an excellent educational adjunct for basic anatomy, the equipment fails to show anatomical variations. Therefore, students agreed that the Anatomage aided them in increasing their anatomical knowledge, recognizing that it is a supplement to the cadavers, rather than a tool that stands on its own.

One limitation, out of the 99 undergraduate participants, exclusively 63 completed the post-test due to technical problems with the online examination tool. Even so, 63 students are enough to obtain our results and affirm our conclusions since it is an acceptable sample size. An additional restriction was ground transportation to mobilize the students from one campus to the other. We conceive if we had had the means of free transportation, the number of participants in this activity would have increased. All the same, the 99 students who attended to participate were highly motivated to travel on their private transportation, and the $\mathrm{AOO}$ aided them in learning human anatomy.

Consequently, we conclude that $\mathrm{AOO}$ yielded great results in the depth, retention, and application of A\&P knowledge, along with increased involvement and excitement for pursuing either STEM or Allied Health degrees. The future goals are to encourage additional graduate students to participate as Teacher Assistants in the AOO since it is established that peer teaching learning is an outstanding strategy for students to consolidate their previous knowledge (Knobe et al., 2010; Jackson and Bruegmann, 2009). Besides, we would like to target other schools with anatomy in their curriculum without a cadaver laboratory and expose them to the AOO. One final note, PCOO, is considering a biannual "Anatomy Week" to encourage and motivate more students to pursue their education in STEM and Allied Health fields.

\section{Author contributions:}

Authors equally contributed.

\section{Ethics and Consent:}

The authors used the ARECCI tool to determine and justify that the AOO is classified under the Program Quality Improvement, for which the ARECCI tool is recommended instead of a Institutional Review Board. 


\section{Acknowledgements}

We gratefully acknowledge the contribution of the Texas Woman's University (PT \& OT Programs) Dallas and Denton (Biology Program), PCOO Members, as well as Aneesah Hyder help during this initiative. Also, we wish to thank the TWU Denton A\&P laboratory coordinator, Mrs. Shaumarie Tanner, for her help in recruiting the students who participated in the activity. We also thank Dr. Dale Anderle for his participation in the AOO during the orientation to the students. Finally, we want to thank all of the graduate students who participated in the activity for teaching the undergraduate students and answering questions.

\section{Disclosure of interest}

All authors report no conflict of interest.

\section{References}

Anatomage [Internet] 2019. Anatomage Table c2004-2019 [accessed 2018 December 15; 2018 April]. Available from: https://www.anatomage.com/

Aziz, M. A., Mckenzie, J. C., Wilson, J. S., Cowie, R. J., Ayeni, S. A., Dunn, B. K. 2002. The human cadaver in the age of biomedical informatics. The Anatomical Record. 269(1): 20-32.

Bavis, R. W., Seveyka, J., Shigeoka, C. A. 2000. Another strategy for teaching histology to A\&P students: classification versus memorization. The American Biology Teacher: 365-369.

Bergman, E. M., Prince, K. J., Drukker, J., van der Vleuten, C. P., Scherpbier, A. J. 2008. How much anatomy is enough?. Anatomical sciences education, 1(4): 184-188.

Biasutto, S. N., Caussa, L. I., del Río, L. E. C. 2006. Teaching anatomy: cadavers vs. computers?. Annals of Anatomy-Anatomischer Anzeiger, 188(2): 187-190.

Brenton, H., Hernandez, J., Bello, F., Strutton, P., Purkayastha, S., Firth, T., Darzi, A. 2007. Using multimedia and Web3D to enhance anatomy teaching. Computers \& Education, 49(1): 32-53.

Chopin, S. F. 2002. Undergraduate research experiences: The translation of science education from reading to doing. The Anatomical Record, 269(1): 3-10.

González-Solá, M. and Rosario-Canales, M. 2015. Encouraging Puerto Rican High School Students to Pursue a STEM Career Through an Anatomy \& Neurobiology Outreach. Faseb J Vol.29 (1) No. 693.6

Jackson, C. K., Bruegmann, E. 2009. Teaching students and teaching each other: The importance of peer learning for teachers. American Economic Journal: Applied Economics, 1(4): 85-108.

Knobe, M., Münker, R., Sellei, R. M., Holschen, M., Mooij, S. C., Schmidt-Rohlfing, B., Pape, H. C. 2010. Peer teaching: a randomised controlled trial using student-teachers to teach musculoskeletal ultrasound. Medical education, 44(2): 148-155.

Lunsford, B. E., Herzog, M. J. R. 1997. Active learning in anatomy \& physiology: Student reactions \& outcomes in a nontraditional A\&P course. The American Biology Teacher: 80-84. 
Momsen, J. L., Long, T. M., Wyse, S. A., Ebert-May, D. 2010. Just the facts? Introductory undergraduate biology courses focus on low-level cognitive skills. CBE—Life Sciences Education, 9(4): 435-440.

Pearson's Mastering A\&P [Internet] 2019. PAL 3.0 c1996-2019 [accessed 2018 April; 2017 November]. Available from: https://www.pearsonmylabandmastering.com/northamerica/masteringaandp/

Shigeoka, C. A., Bavis, R. W., Seveyka, J. 2000. Teaching musculoskeletal anatomy: a technique for active learners. The American Biology Teacher: 198-201.

Sola, M. G., Rosario, M. G. 2018. Human Cadaver Observational Anatomy Outreach Activity for TWU Undergraduates. Faseb J Vol. 32, No. 1.

Texas Woman's University [Internet] 2019. Biology c1957-2019 [accessed 2018 December 15]. Available from: https://twu.edu/biology/ 